\title{
A Comparative Study on the Hepatoprotective E ffect of Tamarindus indica and Vitamin E in Long Evans Rats
}

\author{
NJ Shammi ${ }^{1}$, ZK Choudhry2 ${ }^{2}$ MI Khan ${ }^{3}$, and M M Hossain 4 \\ ${ }^{1}$ Department of General and D ental Pharmacology, Marks D ental College, D haka \\ ${ }^{2}$ D epartment of Pharmacology, Marks M edical College, D haka; \\ ${ }^{3}$ D epartment of Pharmacology, Dhaka M edical College, Dhaka; \\ ${ }^{4}$ D epartment of Anatomy, Kumudini Women's M edical College, M irzapur, Tangail
}

\begin{abstract}
The protective effects of ethanolic extract of Tamarindus indica leaves and seeds in compoarison to vitamin $E$, were studied on paracetamol induced hepatotoxicity in L ong Evans Rats. Different groups of animals were administered in the paracetamol $(1500 \mathrm{mg} / \mathrm{kg}, \mathrm{p.o}$.) for 7 days. Ethanolic extracts of leaves and seeds of Tamarindus indica $(1250 \mathrm{mg} / \mathrm{kg})$ with parallel vitamin $\mathrm{E}(500 \mathrm{mg} / \mathrm{kg})$, were administered to paracetamol pretreated rats. On treatment with paracetamol a significant increase in alanine aminotransferase (ALT), aspartate aminotransferase (AST), total bilirubin and alkaline phosphatase were observed. On administration of ethanolic extracts of leaves and seeds a significant decrease in the level of alanine aminotransferase (ALT), aspartate aminotransferase (AST), total bilirubin and alkaline phosphatase (ALP) were observed and histopathological examination of liver tissue revealed an almost return to normal architecture. The result were almost comparable to vitamin $E$, a known hepatoprotective agent.
\end{abstract}

Key words: Hepatoprotective agent, Tamarindus indica, V itamin E

\section{Introduction}

Vitamin $E$, known to be a hepato-protective agent, is being used by physicians to treat liver diseases. Studies show that use of vitamin $E$ in carbon tetrachloride induced hepatotoxicity helped return of hepatic damage to almost normal architecture ${ }^{1}$. Liver is very vulnerable to damage as it is the principle organ of biotransformation in the body. Severe acute liver disease is encountered in clinical practice leading to fulminant or acute liver failure2. M ost common causes of fulminant hepatic failure include drug or toxin induced hepatic injury or viral hepatitis ${ }^{3}$. Certain medicinal agents, when taken in overdoses and sometimes even when introduced within therapeutic ranges, may be the cause of liver injury. Incidence of fatality due to drug induced liver damage is very high. Some of the commonly used drugs like aspirin, halothane, methyldopa, acetaminophen etc. cause hepatotoxicity.

In Bangladesh, about 35 million people are suffering from liver diseases ${ }^{4}$ and $80 \%$ of death is due to fulminant hepatic failure 5 .
Though liver disease is a worldwide problem, available remedies are scarce. Conventional drugs used in the treatment of liver diseases are inadequate and can have serious adverse effects. Due to lack of reliable allopathic drug to cure liver damage researchers look for herbal drugs with better hepatoprotective action. Several studies have been carried out to see hepatoprotective effect of plants such as Semecarpus anacardium ${ }^{6}$, Aerva lanata ${ }^{7}$, Costus speciosus ${ }^{11}$ and Cleome viscosa8.

Studies suggest that hepatoprotective effect of Tamarindus indica is due to the presence of flavonoids, ascorbic acid and -carotene. Hepatoprotective effect of Tamarindus indica (Family- Caesalpiniaceae), commonly known as tentul, has been studied using aqueous extracts of leaf ${ }^{9}$, fruit ${ }^{10}$ and seed ${ }^{9}$. In the present study ethanolic extracts of leaf and seed of Tamarindus indica were used to see whether the ethanolic extracts is more effective than aqueous extracts and its effect was compared with vitamin $\mathrm{E}$. 
64 Bangladesh J M ed Biochem; 6(2)

\section{$M$ aterials and $M$ ethods}

Plant Materials

Leaves and seeds of Tamarindus indica were procured from Sirajganj and identified by plant taxonomy Unit of Bangladesh $\mathrm{N}$ ational Herbarium with accession no. DACB-35524, which was deposited to the Herbarium.

Preparation of Plant extracts

Leaves and seeds were shade dried and powdered by electric blender and grinder machine. The powders were soaked separately in $95 \%$ ethanol. The extract so obtained was concentrated in vacuum rotatory evaporator at $40-50{ }^{\circ} \mathrm{C}$ until a paste was formed. Extract paste was freeze dried.

D rugs and Chemicals

Paracetamol powder was obtained from Kumudini Pharmaceuticals Ltd, Bangladesh. Propylene glycol was used as solvent for paracetamol powder. Vitamin E solution was collected from Drug international $L t d$, Bangladesh.

\section{Animals}

A total of 30 male Long Evans rats (150-180 gm) were used for this study. The animals were kept in well ventilated room in the animal house of Dhaka M edical College. A $12 \mathrm{hr}$ light/12 hr dark cycle was maintained. They were given standard food pellets and allowed drinking water ad libitum. Ethical clearance for the use of animals was obtained from the Committee constituted for the purpose.

\section{M ethodology}

A total of thirty rats were taken and divided into five groups. Each group having six rats $(n=6)$. Control group received normal diet ad libitum. Only paracetamol group received paracetamol ( $1500 \mathrm{mg} / \mathrm{kg}$ ) for 7 days and three groups received paracetamol $(1500 \mathrm{mg} / \mathrm{kg})$ for first 7 days followed by ethanolic extract of leaf $(1250 \mathrm{mg} / \mathrm{kg})$ and seed $(1250 \mathrm{mg} / \mathrm{kg})$ of Tamarindus indica and vitamin $\mathrm{E}(500 \mathrm{mg} / \mathrm{kg})$ for next 5 days.
NJ Shammi, ZK Choudhry, MI Khan, M M Hossain

After 24 hours of last treatment, all rats were anesthetized with light chloroform and blood was collected by cardiac puncture and serum was separated for estimations of serum alanine aminotransferase (ALT), serum aspartate aminotransferase (AST), serum alkaline phosphatase (ALP) and serum bilirubin. Liver was taken for histopathological examination.

Histopathological Study

Liver tissue was taken and fixed in 10\% formalin and sections of liver tissue were embedded in paraffin and made blocks. Serial sections of blocks $3 \mu-5 \mu$ thickness were made and stained with haematoxylin and eosin and examined under microscope.

Statistical Analysis

The values were expressed as mean $\pm S D$. The statistical analysis was carried out by unpaired student' $s$ ' $t$ ' test and $p<0.05$ was considered as significant.

\section{Results}

In rats pretreated with paracetamol, serum bilirubin, ALT, AST and ALP increased significantly as compared to control group (Table I). Significant decrease in serum bilirubin, $A L T$, AST and ALP was observed following administration of ethanolic extract of leaf and seed of Tamarindus indica and vitamin E (Table 1). The rate of decline in serum enzyme level following administration of ethanolic extract of leaf and seed of $T$. indica was same as that of vitamin E. Histopathological examination of liver tissue in Paracetamol administered rats showed massive liver tissue necrosis with loss of cellular architecture and infiltration of neutrophil, macrophage and lymphocyte (Fig: 2). An almost return to normal architecture of hepatic tissue was observed in rats that received ethanolic extract of leaf and seed of Tamarindus indica (Fig: $3 \& 4$ ). Similar texture and cell arrangement were observed in the liver section of rats treated with vitamin E (Fig: 5). 
Hepatoprotective Effects of $\mathrm{T}$ indica and Vit $\mathrm{E}$

Table I: Serum bilirubin, ALT, AST and ALP level in Paracetamol pretreated (7 days) rats that received ethanolic extract of leaf and seed of Tamarindus Indica and vitamin $E$.

\begin{tabular}{lcccc}
\hline Groups & $\begin{array}{c}\text { Serum } \\
\text { bilirubin }\end{array}$ & $\begin{array}{c}\text { Serum } \\
\text { ALT (U/L) }\end{array}$ & $\begin{array}{c}\text { Serum } \\
\text { AST (U/L) }\end{array}$ & $\begin{array}{c}\text { Serum } \\
\text { ALP (U/L) }\end{array}$ \\
\hline Control & $\begin{array}{c}0.45 \pm 0.13 \\
\text { (mg/dl) }\end{array}$ & $41.33 \pm 4.45$ & $36.33 \pm 3.44$ & $90.00 \pm 12.59$ \\
& $1.06 \pm 0.48^{* *}$ & $193.00 \pm 12.87^{* * *}$ & $166.00 \pm 19.67^{* * *}$ & $428.00 \pm 33.66^{* * *}$ \\
$\begin{array}{l}\text { Only Paracetamol } \\
(1500 \mathrm{mg} / \mathrm{kg})\end{array}$ & & & & \\
Leaf extract T. indica & $0.65 \pm 0.17^{*}$ & $61.33 \pm 2.50^{* * *}$ & $50.33 \pm 1.63^{* * *}$ & $174.00 \pm 22.45^{* * *}$ \\
$\begin{array}{l}(1250 \mathrm{mg} / \mathrm{kg}) \\
\text { Seed extractT.indica }\end{array}$ & $0.57 \pm 0.20^{*}$ & $60.17 \pm 4.54^{* * *}$ & $53.00 \pm 5.59^{* * *}$ & $178.00 \pm 27.80^{* * *}$ \\
$(1250 \mathrm{mg} / \mathrm{kg})$ & & & & \\
Vitamin-E & $0.52 \pm 0.18^{*}$ & $55.33 \pm 4.08^{* * *}$ & $47 . .67 \pm 6.06^{* * *}$ & $142.00 \pm 17.66^{* * *}$ \\
$(500 \mathrm{mg} / \mathrm{kg})$ & & & & \\
\hline
\end{tabular}

$\mathrm{n}=6$. All the drugs were administered orally through Ryles tube. Data expressed as mean $\pm S D$. $* * * P<0.001$.

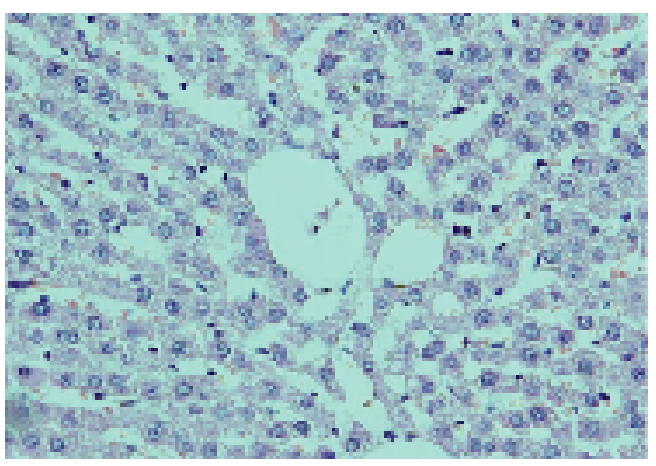

Fig-1 : Photomicrographs 40X showing the normal hepatic architecture in control group.

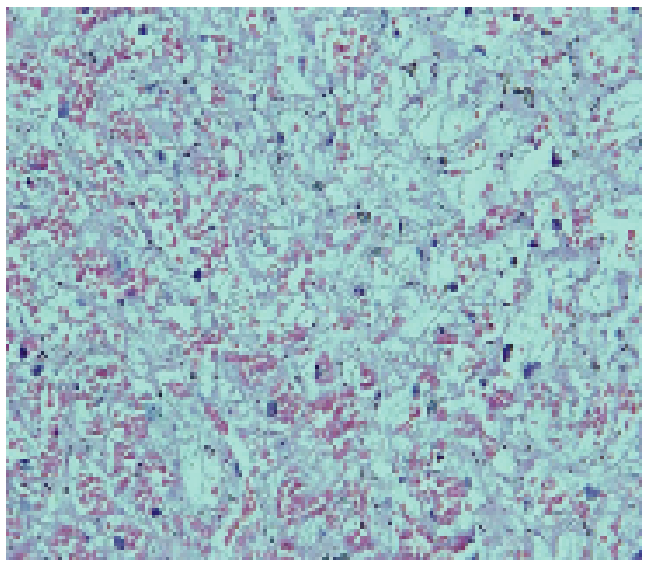

Fig-2: Photomicrographs 40X showing Paracetamol induced hepatic necrosis and small number of inflammatory cells.

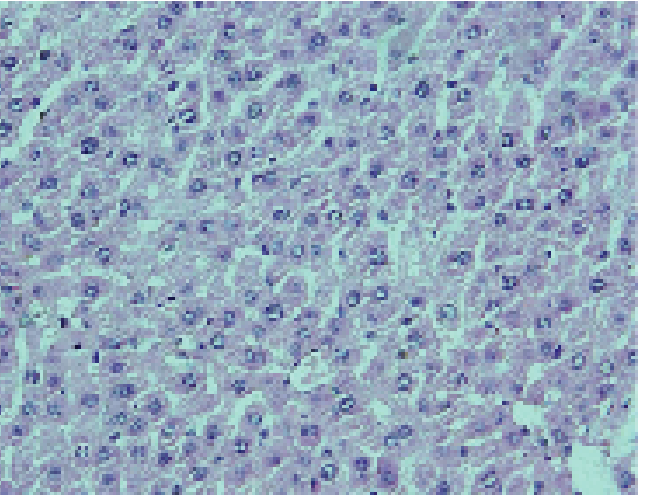

Fig-3: Photomicrographs 40X showing normal hepatic architecture following administration of leaf extract of Tamarindus indica in Paracetamol induced hepatotoxicity

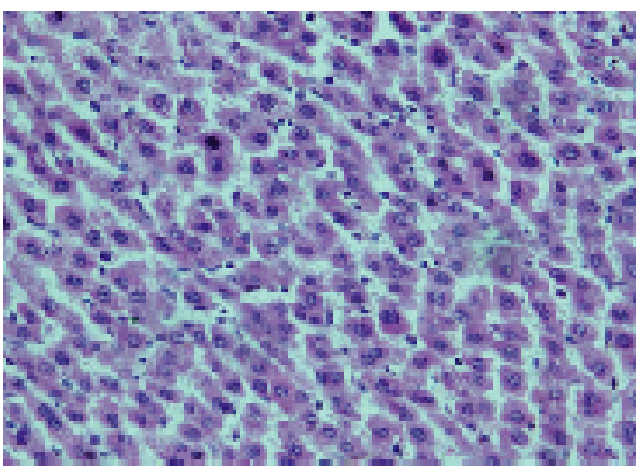

Fig-4: Photomicrographs 40X showing normal hepatic architecture following administration of seed extract of Tamarindus indica in Paracetamol induced hepatotoxicity.

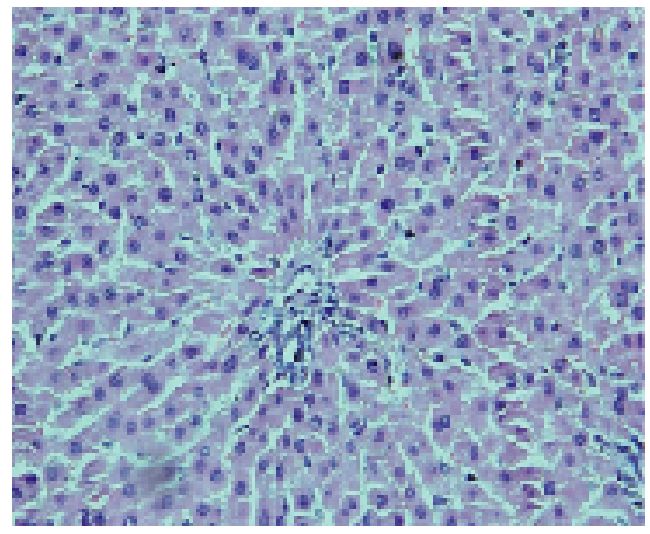

Fig--5: Photomicrographs (M agnification at 10X and 40X objectives) showing normal hepatic architecture following administration of Vitamin $E$ in Paracetamol induced hepatotoxicity. 
NJ Shammi, ZK Choudhry, MI Khan, M M Hossain

\section{Discussion}

Significant increase in serum bilirubin, $A L T$, AST and ALP following administration of paracetamol is an indicator of hepatotoxicity. A ssessment of liver damage can be assessed by estimation of serum ALT, AST and ALP9. $\mathrm{Necrosis}$ results in the release of these enzymes into circulation, therefore, it can be measured in serum. High levels of AST indicate liver damage, ALT catalyses the conversion of alanine to pyruvate and glutamate and is released in similar manners, therefore, ALT is more specific to liver and is thus a better parameter for detecting liver damage ${ }^{12}$.

The results in the present study showed a significant damage to liver tissue following administration of paracetamol, confirmed by histopathological examination of liver tissue that showed massive necrosis and infiltration of macrophages and lymphocytes.

Paracetamol causes acute liver damage ${ }^{15}$ due to depletion of glutathione and formation of highly reactive metabolite $\mathrm{N}$-acetyl Parabenzoquinoneimine (NAPQI)14. NAPQI arylates essential nucleophilic macromolecules within hepatocytes, forming stable acetaminophen-protein adducts which are responsible for A cetaminophen induced hepatotoxicity ${ }^{13}$. Elevated enzyme levels showed loss of functional integrity of hepatocytes ${ }^{16}$. Administration of ethanolic extracts of leaf and seed of Tamarindus indica decreased liver enzymes level and helped return of liver tissue to almost normal architecture on histopathological examination, which is same as that of vitamin E. Similar other studies have been carried out using aqueous extract of leaf 9 , seed $^{9}$ and fruit ${ }^{10}$ extracts of Tamarindus indica and similar results were observed. From this study it can be assumed that both Tamarindus indica and vitamin $\mathrm{E}$ are hepatoprotective and their hepatoprotective effect is almost equal. Hepatoprotective effect of vitamin $E$ is due to its antioxidant property. Hepatoprotective effect of Tamarindus Indica has been attributed to the presence of flavonoids, polyphenol, -carotene and ascorbic acid18. A number of scientific reports indicate that flavonoids, -carotene, ascorbic acid have protective effect on liver due to their antioxidant properties ${ }^{17}$.

It seems that Tamarindus indica, a very commonly used food, can be applied for treatment of drugs or chemical induced hepatotoxicity. Use of natural products cause less adverse effect compared to synthetic analogues. Tamarindus indica is easily available, cheap and its fruit is consumed as a popular food. Considering its availability and cheapness and its comparable effectiveness to vitamin $E$, it might be considered as a hepatoprotective agent and applied in the treatment of drug related hepatotoxicity. Before clinical application further studies on its beneficial hepatoprotective effect showed be carried out.

\section{R eferences}

1. Sadeque MJ, Begum JA, U mar BU, Ferdous AH, Sultana $S$, Uddin MK . Comparative Efficacy of Dried fruits of Carica Papaya Linn. and Vitamin $E$ on Preventing Hepatotoxicity in Rats. Faridpur M ed Coll J 2012; 7: 29-32.

2. Finlayson NDC, Hayes NC and Simpson KJ. Diseases of the liver and biliary system. In: Haslett C, Chilvers ER, Hunter J, editors. Davidson's Principle and Practice of Medicine. 18th ed. Churchill Livingstone, Harcaurt Brace and Company 1999: 683-736.

3. Lidofsky SD. Liver transplantation for fulminant hepatic failure. Gastroenterol Clinic North A mer 1993; 22: 257-269.

4. Khan M. 35 million people suffer from liver disease in Bangladesh. The Financial Express, October 28, 2010.

5. Alam S, Azam G, M ustafa G, Azad AK, Gani S. $N$ atural course of fulminant hepatic failure: the scenario in Bangladesh and the differences from the West Saudi. J Gastroenterol 2009; 15: 229-233. 
6. Kangralkar VA, Patil SD, Bandivadekar RM, Nandagaon VS, Burli SC. Hepatoprotective activity of Feronia elephantum fruit extract against paracetamol induced hepatic damage in wistar rats. Intern J pharma A ppl 2010; 1: 46-49.

7. Manokaron S, Jaswanth A, Sengottuvelu S , N andhakumar J. Hepatoprotective activity of A erva lanata Linn. against Paracetamol induced hepatotoxicity in rats. Res J pharm Tech 2008; 1: 398-400.

8. M obiya A K, Patidar A K, Selvam G, Jeyakandan $M$. Hepatoprotective effect of Cleome viscose $L$ seeds in Paracetamol induced hepatotoxic rats. Intern J pharma Bio arch 2010; 1: 399-403.

9. Pimple BP, Kadam PV, Badgujar NS, Bafna AR, Patil MJ. Protective effect of Tamarindus indica Linn against paracetamol induced hepatotoxicity in rats. Ind J Pharma Sci 2007; 69: 827-831.

10. Ranjan R, Swarupa D, Patra RC, Vikas C. Tamarindus indica and Moringa oleifera extract administration ameliorates fluoride toxicity in rabbits. Indi J Exp Biol 2009; 47: 900-905.

11. Verma $N \&$ K hosa $R L$. Evaluation of protective effects of ethanolic extract of Costus speciosus rhizomes on carbon tetrachloride induced hepatotoxicity in rats. Natural Product Radiance 2009; 8: 123-126.
12. Willianson EM, Okpako DT, Evans FJ. Selection, Preparation and Pharmacological evaluation of plant material. England: John Wiley; 1996.

13 A deneye A A, Olagunju J O. Protective effect of oral ascorbic acid (Vitamin C) against A cetaminophen induced hepatic injury in rats. Afr J Biomed Res 2008; 11: 183-190.

14. Farrell GC. Drug induced liver disease. Churchill livingstone publication, Edinburgh. 1994.

15. Lee WN. Drug induced hepatotoxicity. New Eng J M ed 1995; 333: 1118.

16. Lima FC, Souza DF, Ferreira JM, Campos AR. Croton zehntneri essential oil prevents A cetaminophen induced acute hepatotoxicity in mice. Records of natural products 2008; 2: 135-140.

17. Olatunde FE, Oluwatosin AA,Godwin EO. Influence of chloramphenicol on rat hepatic microsomal components and biomarkers of oxidative stress: Protective role of antioxidants. Pharmacol Toxicol 2002; 91: 129-134.

18. Ross IA. Medicinal plants of the world. Chemical constituents, traditional and modern medicinal uses. 2nd ed. N ew Jersey: Humana Press; 2004. 